\title{
Comment on Dattani et al: Navigation knee replacement
}

\author{
C. Schnurr • D. P. König
}

Received: 20 March 2009/Accepted: 18 April 2009/Published online: 8 May 2009

(C) Springer-Verlag 2009

\section{Dear Editor,}

We read the article by Dattani et al. [1] concerning effectiveness and cost of computer-navigated total knee arthroplasty (TKA) with interest. It is essential to determine potential benefits, drawbacks and cost of computer navigation to assess the value of this relatively new technology. In a study of our own (presented at the DGOU meeting, October 22-25, 2008 in Berlin, Germany), we compared conventional and computer-navigated total knee replacements. Computer navigation significantly reduced imperfections and improved the mechanical axis. Costs for computer navigation were calculated as $442 €$ per navigated operation for our hospital. Further analysis of our data revealed a significantly reduced blood loss and transfusion rate for the navigated implanted prostheses. These results are consistent with another cited study [2]. Unfortunately, in this context, two other citations in the article of Dattani et al. are incorrect: the study of Bierbaum et al. [3] did not record data about computer navigation at all, and Stulberg et al. [4] did not report details of blood loss or blood transfusions.

From our point of view, in addition to the comments on the Dattani article, another positive aspect of computer navigation should be mentioned, that is, the intraoperative feedback with regard to resection, ligament balancing, and limb alignment provided by computer-assisted surgery which offers surgeons an opportunity to improve their judgment with regard to the accuracy with which they perform and evaluate each step of the total knee arthroplasty procedure [5]. Therefore, computer-assisted surgery has the potential to function as a highly effective teaching tool in training orthopaedic residents and less experienced surgeons on how to perform knee reconstructions more accurately.

\section{References}

1. Dattani R, Patnaik S, Kantak A, Tselentakis G (2009) Navigation knee replacement. Int Orthop 33:7-10

2. Kalairajah Y, Simpson D, Cossey AJ, Verrall GM, Spriggins AJ (2005) Blood loss after total knee replacement: effects of computerassisted surgery. J Bone Joint Surg Br 87:1480-1482

3. Bierbaum BE, Callaghan JJ, Galante JO, Rubash HE, Tooms RE, Welch RB (1999) An analysis of blood management in patients having a total hip or knee arthroplasty. J Bone Joint Surg Am 81:210

4. Stulberg SD, Loan P, Sarin V (2002) Computer-assisted navigation in total knee replacement: results of an initial experience in thirty-five patients. J Bone Joint Surg Am 84-A(Suppl 2):90-98

5. Stulberg SD, Yaffe MA, Koo SS (2006) Computer-assisted surgery versus manual total knee arthroplasty: a case-controlled study. J Bone Joint Surg Am 88(Suppl 4):47-54 